УДК 336.64

Л. В. Кислицына

Байкальский государственный университет, г. Иркутск, Российская Федерация

H. С. Суворов

Байкальский государственный университет,

г. Иркутск, Российккая Федераиия

\title{
АКТУАЛЬНЫЕ ВОПРОСЫ ОРГАНИЗАЦИИ ПРОЦЕССА ФИНАНСИРОВАНИЯ ПРЕДПРИЯТИЙ МАЛОГО БИЗНЕСА
}

\begin{abstract}
АНнотАЦия. В статье дается краткая характеристика роли и значения малого бизнеса в экономике и реализуемых мер по его поддержке в настоящее время. Обоснована актуальность исследования вопросов финансирования малого бизнеса с целью поиска возможных резервов его развития. Рассмотрены подходы к определению понятия «финансирования». Сформулирован вывод о необходимости создания условий для полноценного функционирования альтернативных источников финансирования в условиях макроэкономической нестабильности. Проводится аналогия в части организации процесса финансирования малого и крупного бизнеса. Выделяются особенности финансирования малых предприятий. Определена роль личных финансов в реализации пассивного финансирования малого бизнеса. Представлена авторская позиция в отношении роли активного финансирования для развития финансов малого бизнеса. Выделены направления трансформации финансирования малого бизнеса в современных условиях. Дополнена классификация финансирования в части выделения активно-пассивного финансирования.
\end{abstract}

КЛЮчЕВЫЕ сЛОВА. Малый бизнес; финансирование; лизинг; факторинг; венчурный капитал; краудфандинг; краудинвестинг; личные финансы.

ИНФОРМАЦИЯ О СТАТЬЕ. Дата поступления 12 апреля 2016 г.; дата принятия к печати 5 мая 2016 г.; дата онлайн-размещения 29 июля 2016 г.

L. V. Kislitsyna Baikal State University, Irkutsk, Russian Federation

N. S. Suvorov Baikal State University, Irkutsk, Russian Federation

\section{TOPICAL ISSUES OF THE SMALL BUSINESS FUNDING ORGANIZATIONAL PROCESS}

ABSTRACT. The article presents a brief characteristic of small business importance in the economy and implementation measures of its support at the present time. It substantiates the topicality of studying small business funding issues with the aim of searching possible reserves of its development, considers approaches to definition of the "funding " concept. It draws up a conclusion about the necessity of creating conditions for full-rate functioning of alternative funding sources in terms of macroeconomic instability. It brings forth an analogy concerning organizing the funding process for small and large business and specifies the features of small business funding. The article presents the author's position in regard to the role of active funding for developing small business finance. It identifies the trends of small business funding transformation; it adds a classification of funding in relation to making active-passive funding.

KEYWORDS. Small business; funding; leasing; factoring; venture capital; crowd-funding; crowd-investing; personal finance.

ARTICLE INFO. Received April 12, 2016; accepted May 5, 2016; available online July $29,2016$.

\section{Baikal Research Journal}


Уровень развития малого и среднего бизнеса во многом определяет уровень экономики любого государства в настоящее время. Данные предприятия в силу присущей им мобильности обладают возможностью сглаживать негативные процессы в сфере занятости населения, создавать новые рыночные ниши и точки экономического роста, а также за счет высокой ликвидности капитала обеспечивать его окупаемость в короткие сроки путем перехода из одной сферы деятельности в другую. Однако в то же время малые и средние предприятия наиболее уязвимы в период кризиса, нестабильной экономической и политической ситуации [1].

По состоянию на сегодняшний день в малом и среднем бизнесе России свою деятельность ведут порядка 6 млн субъектов, на которых официально занят каждый четвертый работник. При этом на малые и средние компании приходится всего лишь не более 6 \% от общего объема основных средств и от объема инвестиций в основной капитал ${ }^{1}$. За последнее время их вклад в валовой внутренний продукт (ВВП) незначительно увеличился и достиг чуть больше $20 \%$, что является довольно низким показателем в сравнении с развитыми странами, где доля данного сектора экономики составляет более половины. Так, в США этот показатель отмечен на уровне $52 \%$, В Японии - $55 \%$, в странах Евросоюза - $67 \%$.

Развитию малого бизнеса в России уделяется значительное внимание. Так, к настоящему моменту созданы организационные и нормативно-правовые основы его государственной поддержки. В частности, реализуется ряд масштабных программ, в рамках которых во всех регионах страны предприниматели имеют возможность получить грант на открытие собственного дела, микрозаимствования, гарантию по кредиту или кредит на льготных условиях. Для малых предприятий предусмотрены также специальные налоговые режимы, позволяющие оптимизировать систему учета и налоговых платежей [2; 3]. Существенным образом повышается доступность малых предприятий к закупкам органов государственной власти и государственных корпораций. Есть определенные достижения в части информационно-консультационной и имущественной поддержки бизнеса. Так, в частности, с каждым годом увеличивается количество бизнес-инкубаторов, центров развития бизнеса, инновационных центров и центров поддержки экспорта. Особое значение уделяют в данном случае организации и функционированию муниципальных бизнес-инкубаторов [4]. Считается, что их роль значительна в развитии малого бизнеса на местном уровне. По мнению О. В. Чистяковой, муниципальные бизнес-инкубаторы могут оказывать широкий спектр услуг в части комплексной поддержки как вновь создаваемых, так и действующих малых предприятиях на различных стадиях их развития. Бизнес-инкубаторы отличаются гибкостью, что создает возможность адаптироваться $к$ изменениям спроса со стороны предпринимательского сообщества, а также учитывать приоритеты развития территории [5].

На сегодняшний день основными сдерживающими факторами развития малого и среднего предпринимательства оказались нестабильный курс национальной валюты, неопределенность экономической ситуации, высокий уровень налогообложения, снижающийся спрос на продукцию на внутреннем рынке наряду с введением торговых санкций. В сложившихся условиях наибольшие потери несут такие направления деятельности, как оптовая и розничная торговля, строительство, общественное питание, а также транспорт - а именно на них традиционно приходится основная доля малого бизнеса.

Безусловно, совокупность перечисленных мероприятий не умаляет роль поиска резервов, в том числе и внутренних, для поддержания жизнедеятельности малого бизнеса, а в дальнейшем и для определения направлений развития. По нашему мне-

${ }^{1}$ Доклад «О мерах по развитию малого и среднего предпринимательства в Российской Федерации» / Гос. Совет РФ. М., 2015. 82 с.

\section{Baikal Research Journal}

электронный научный журнал Байкальского государственного университета 
нию, одним из основных актуальных вопросов в данном случае является организация процесса финансирования.

Считаем целесообразным в данном случае привлечь внимание к понятию «финансирование» как таковому. Так, определенная часть экономистов дает определение финансирования как некоторого события, факта, причем, рассматривая его в одностороннем порядке, не раскрывая данного явления как двустороннего процесса: это «обеспечение необходимыми ресурсами затрат на развитие национальной экономики, социально-культурных мероприятий, оборону и другие общественные потребности», «обеспечение финансовыми ресурсами всего хозяйства страны, регионов, предприятий, предпринимателей...», «привлечение средств», «обеспечение хозяйственной деятельности предприятия денежными ресурсами, необходимыми для покрытия затрат различного характера» [6]. Однако с точки зрения практической организации данного процесса финансирование включает в себя наравне с выбором форм, методов и источников привлечения капитала выбор решений по поводу выбора направлений их использования.

Другими словами, для предприятий малого и среднего бизнеса понимание процесса финансирования аналогично крупным компаниям. Характеристика содержания финансирования в данном случае также предполагает изучение не только финансового обеспечения, но и второй его составляющей, а именно направленности использования привлеченных ресурсов. Значимость последнего определяется тем, что организация процесса финансирования предполагает на практике осуществление выбора направлений использования привлеченного капитала. Принятие решений в данном случае включает в себя не только выбор форм, методов и источников привлечения капитала, но и направлений использования привлеченного капитала на цели вложения (инвестирования), авансирования и расходования [7]. Каждое из названных направлений подразумевает их наполнение источниками финансирования и обязательствами, а также формирование результатов.

Следовательно, без акцентирования внимания на двусторонности данного процесса не представляется возможной полная характеристика данного понятия с одной стороны, а с другой - обеспечение определенной результативности того или иного направления использования капитала (инвестирование, авансирование и расходование) создает возможности для задействования наряду с пассивным, так называемого активного финансирования.

Как известно, активное финансирование подразумевает совокупность операций, имеющих качественно однородную особенность, предполагающую высвобождение капитала в границах предприятия в результате использования активов. Высвобождение капитала в данном случае может быть организовано в форме финансовых потоков, высвобождающих капитал, или потоков, генерируемых в результате ускорения оборачиваемости капитала. В первом случае первостепенная роль отводится выручке от продаж товаров, работ и услуг. При этом основное внимание уделяется с позиции воспроизводственного подхода обязательному возмещению ранее авансированного капитала. Полную оценку результативности этого направления финансирования можно представить, обособляя в составе выручки величину амортизации, поскольку ее основной целью является именно возмещение в процессе кругооборота ранее инвестированного капитала.

Результатом активного финансирования, реализуемого путем продажи отдельных видов активов, в том числе непрофильных, в отдельных случаях является существенное сокращение потребности во внешнем финансировании или потребности в накоплении собственного капитала. При этом очевидным является факт перераспределения капитала между мобильными и немобильными активами, а также вывод имущества с предприятия.

\section{Baikal Research Journal}

электронный научный журнал Байкальского государственного университета 
Позволяет также сократить потребность во внешних финансовых ресурсах активное финансирование в форме ускорения оборачиваемости ранее вложенного капитала. При этом оно напрямую зависит от качества финансовых решений менеджмента. Ускорение оборачиваемости в данном случае может быть обеспечено различным образом. Во многом ему способствуют: повышение эффективности политики управления запасами, совершенствование технологического процесса, ускорение процесса реализации продукции за счет упорядочения документооборота, моделирование кредитной политики с покупателями и др.

Разновидностью активного финансирования является факторинговое финансирование. Факторинг является одной из относительно новых в России форм финансирования, способных решить определенную часть проблем малых предприятий в части финансового обеспечения. Как отмечается в обзоре ассоциации факторинговых компаний, по итогам первого полугодия 2015 г. совокупный оборот российского рынка факторинга составил 830 млрд р., доля же сегмента малого бизнеса в этом обороте составляет примерно $16 \%$. По сравнению с первым полугодием прошлого года она сократилась на $4 \%$. В отраслевой структуре преобладают по-прежнему такие традиционные для факторинга отрасли, как производство и продажа продуктов питания и строительно-отделочных материалов.

За анализируемый период времени услугами факторинга воспользовались свыше 3 тыс. малых и средних компаний и индивидуальных предпринимателей, что составляет $61 \%$ от совокупной клиентской базы рынка (около 6100 компаний). В сегменте малого и микробизнеса на одного клиента за 6 мес. 2015 г. приходится от 9 до 49 млн р. оборота, в сегменте среднего бизнеса - до 200 млн р.

Важно отметить, что популярность данного способа финансирования обеспечивается дефицитом иных источников. Так, в связи с ужесточением условий кредитования, а также с сокращением сроков отсрочки платежей со стороны поставщиков многие предприятия столкнулись с проблемой дефицита ликвидности, что фактически побудило компании к поиску новых источников финансирования, к числу которых относится и факторинг.

Пассивное финансирование в свою очередь представляет собой мобилизацию капитала в распоряжение менеджмента предприятия со стороны различных кредиторов. Результатом пассивного финансирования становится изменение содержания статей источников капитала (пассива баланса).

Традиционно, что при характеристике процесса финансирования малых предприятий приоритет отдается именно пассивному финансированию. Это подтверждают работы В. Ю. Бурова, А. П. Киреенко, М. Г. Лапусты, Л. В. Саниной, А. П. Суходолова, А. Ф. Шуплецова и др.

На протяжении практически всего существования малого и среднего бизнеса их главными финансовыми источниками оставались привлеченные средства кредитных учреждений. Однако ввиду существенного увеличения стоимости заемных средств, переориентации ведущих банков на рефинансирование внешнего долга крупных компаний, а также роста доли краткосрочных кредитов в настоящих экономических условиях актуальной является проблема поиска альтернативных источников пассивного финансирования деятельности предприятий рассматриваемого сектора. Повышение финансовой обеспеченности малых предприятий в данном случае возможно путем применения эффективных финансовых, ресурсосберегающих технологий. Среди таковых можно выделить следующие: лизинговое финансирование, венчурное финансирование и краудфандинг.

Характеризуя роль лизингового финансирования, важно отметить, в первом полугодии 2015 г. объем рынка новых сделок с применением данного вида финансирования сократился примерно на треть, по сравнению с аналогичным периодом

\section{Baikal Research Journal}

электронный научный журнал Байкальского государственного университета 
прошлого года, и составил 244 млрд р. При этом из всего объема заключаемых в России лизинговых сделок более 30 \% приходится на сделки с субъектами малого и среднего предпринимательства ${ }^{2}$. В настоящее время интерес российского рынка лизинговых услуг к малому и среднему бизнесу существенно возрос. В частности, в работе А. П. Суходолова и И. В. Кульдюковой именно малый бизнес рассматривается как перспективное направление деятельности лизинговых компаний. Во-первых, вследствие того, что данный сектор может демонстрировать более динамичный рост, предъявляя большой спрос на финансирование, и готов к достаточно дорогим ресурсам. Во-вторых, собственные средства малых предприятий невелики, а доступ к банковскому финансированию остается ограниченным [8].

Венчурным капиталом в свою очередь оперируют специальные венчурные фонды или индивидуальные инвесторы, часто называемые «бизнес-ангелами». Прежде всего, областью интересов венчурных инвесторов являются промышленная реструктуризация, новые технологии и малый бизнес. Именно данные секторы экономики в полной мере характеризуются как объекты с высоким уровнем риска. Имеет место большое количество определений венчурного финансирования, при этом все их роднит функциональная задача венчурного капитала, а именно способствование росту бизнеса посредством предоставления финансовых ресурсов в обмен на долю участия в капитале. Венчурный капитал как источник финансирования традиционно ассоциируется с реализацией инновационных проектов. На практике имеют место частные, частно-государственные и корпоративные фонды (инвестируют в интереcax корпораций-учредителей) [9]. При этом, по данным компании J'son \& Partners Consulting, в первом полугодии 2015 г. наблюдается определенное снижение активности инвесторов. По сравнению с аналогичным периодом прошлого года российский венчурный рынок показал падение на 33 \% и составил 209,1 млн дол. За данный период аналитики выделили 140 сделок, из которых 115 - это сделки по привлечению нового финансирования (cash-in) на общую сумму 147,7 млн дол. и 25 сделок по продаже существующих долей на сумму 61,5 млн дол. Активность государственных инвесторов, по сравнению с прошлым годом, снизилась практически до $12 \%$.

Рассмотренные источники пассивного финансирования можно отнести к традиционным. При этом считаем актуальным говорить о применении новых для российской практики источников финансового обеспечения. Так, в последние несколько лет особую популярность набирает использование капитала физических лиц, как разновидности финансирования, именуемое краудфандингом, которое основано на финансировании определенных проектов «толпой» с помощью электронных ресурсов, именуемых платформами. Отсутствие ресурсов, необходимых для покрытия текущих потребностей, их нехватка или невозможность быстрой мобилизации препятствует обеспечению эффективного ведения деятельности. Зарубежный опыт применения краудфандинга дает основания утверждать, что этот источник обладает значительным потенциалом для реализации прежде всего коммерческих инновационных проектов. Значительный вклад в развитие научной мысли о краудфандинге внесли главным образом такие зарубежные ученые, как П. Беллефлемм, Дж. Хау, Т. Ламберт, М. О. Душина, И. А. Тян, Г. А. Хмелева и др.

Краудфандинг происходит от английского словосочетания «crowd funding»: crowd - «толпа», funding - «финансирование». Он является моделью финансирования социальных и общественных инициатив или проектов, которая основана на идее группового инвестирования, предполагающей поддержку проекта большим количеством людей. Как правило, финансирование осуществляется с помощью интернет-платформ, что позволяет обеспечить мобилизацию капитала от много-

${ }^{2}$ Эксперт PA [Электронный ресурс] : офиц. сайт рейтинг. агентства. URL : http://www.raexpert.ru.

\section{Baikal Research Journal}

электронный научный журнал Байкальского государственного университета 
численных инвесторов. Различают несколько разновидностей краудфандинга: на основе долевого участия в капитале компании или проекте, также именуемый краудинвестингом, на основе финансового займа - краудфандинговое финансирование в обмен на вознаграждение и краудфандинг на основе пожертвований [10].

Актуальность краудфандинга повышается в настоящее время в виду недостаточности финансовых ресурсов как в частном, так и в публичном секторах экономики, что в некоторой мере вызвано изменением мировой экономической ситуацией. Среди основных преимуществ данного источника финансирования следует выделить: демократичность и прозрачность самой процедуры осуществления процесса финансирования; сокращение времени, затрачиваемого на подготовку сопутствующей документации, а также помощь в развитии малого бизнеса в целом.

Наибольший интерес для проблемы финансирования малого и среднего бизнеса представляет краудинвестинг. Являясь самым «молодым» сегментом отрасли (первые площадки появились только в 2014 г.), он обладает высоким уровнем оперативности (менее чем за год общий оборот средств, собранных через платформы, составил 50-60 млн р.). В краткосрочной перспективе рынок краудинвестинга продолжит расти, однако в России данная бизнес-модель только формируется и, по прогнозам консалтингового агентства «J'son\&Partners», суммарный объем собранных средств составит 0,5 млрд дол. к 2018 г., т. е. $12 \%$ от доли венчурных инвестиций в стране ${ }^{3}$. Учитывая существующие сложности, во время кризиса привлечения иностранных инвестиций, высоких ставок по кредитам и займам, а также массовом отказе банков в кредитовании рискованных проектов - финансирование посредством краудинвестинга может стать для многих наиболее доступным, если не единственным, способом привлечения финансовых ресурсов. Кроме того, важно отметить, что российские банки на сегодняшний день рассматривают краудинвестинговые платформы как потенциальных конкурентов. Однако на практике взаимодействие банковского сектора с краудинвестингом, напротив, может способствовать развитию малого бизнеса [11].

Особенностью названных форм пассивного финансирования, по-нашему мнению, является тесная связь с личными финансами, поскольку одним из основных источников финансового обеспечения в данном случае выступают, прежде всего, финансовые ресурсы населения. Организация личных финансов невозможна без финансового планирования. В общем виде личное финансовое планирование представляет собой управление личными финансами, которое позволяет грамотно распоряжаться денежными потоками физического лица в течение всей его жизни. Типовая ассоциативная схема движения денежных потоков в личном финансовом плане выглядит следующим образом (рис.).

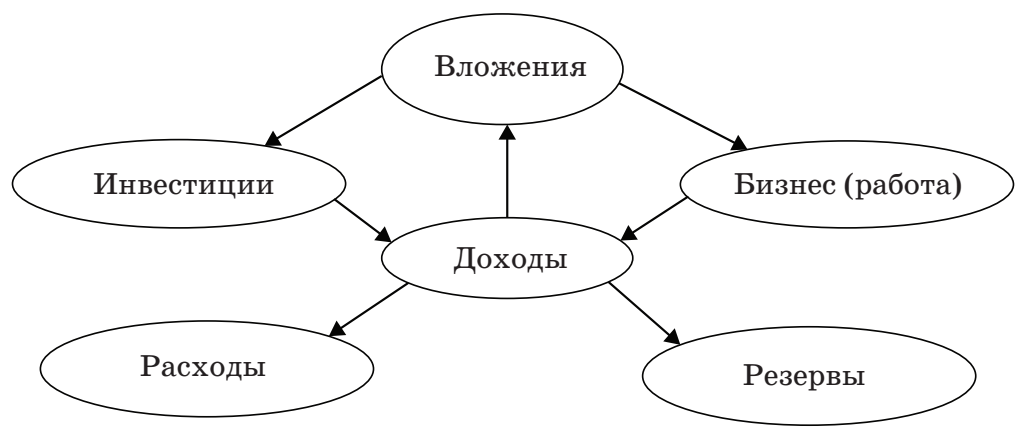

Движение денежных потоков в личнол финансовол плане

${ }^{3}$ J'son\&PartnersConsulting [Электронный pecypc] : офиц. сайт. URL : http://www.json.ru.

\section{Baikal Research Journal}

электронный научный журнал Байкальского государственного университета 
Относительно инвестиций и выбора их вариантов, следует учесть готовность конкретного физического лица к риску, который их сопровождает. Считаем, что краудфандинг в данном случае в полной мере можно рассматривать как объект инвестиций. Здесь особое значение приобретает задача повышения финансовой грамотности, решение которой будет способствовать повышению финансового благополучия граждан с одной стороны и с другой - развитию экономики России в целом.

Примечательно, что повышение потребности предприятий малого и среднего бизнеса в источниках финансирования способствует трансформации этого процесса. Как известно, слово «трансформация» происходит от английской лексемы «transformation», означающей преобразование или превращение. При этом изучая экономические процессы, трансформацию принято рассматривать как особое направление развития. Здесь важно выделять существенное различие между классическим явлением развития и трансформацией. Так, если развитие традиционно предполагает естественную жизнь объекта, организованную по внутренним законам и законам окружающей среды, то трансформация обязательно подразумевает инициированное кем-либо преобразование, основной целью которого является качественное изменение частей объекта либо объекта в целом. Трансформация может быть ориентирована также на изменение направления развития.

В нашем случае целесообразно говорить о трансформации финансирования малого бизнеса как о преобразовании процесса финансирования под влиянием, прежде всего, внешних факторов, которые были уже рассмотрены. Важно отметить, что внешние факторы провоцируют зачастую действие внутренних, в числе которых в настоящее время особо актуальными становятся поведенческих факторы.

Считаем, что одним из результатов трансформации процесса финансирования малого бизнеса является появление новых способов финансирования, которые можно квалифицировать как активно-пассивные. В качестве примера может быть отмечен аутсорсинг определенного вида деятельности. По праву его можно считать перспективным способом финансирования, предполагающим возможность тесного взаимодействия малого и крупного бизнеса, а также государства на условиях государственно-частного партнерства. В то же время развитие государственно-частного партнерства должно основываться на строго определенной законодательной базе. Государству необходимо обеспечить абсолютную прозрачность для скорейшего широкого внедрения финансовых ресурсосберегающих методов для цели увеличения доли предприятий малого бизнеса в ВВП, соответствующей уровню большинства развитых стран. Основой этого направления является передача изготовления части выполняемого заказа партнерам с обязательным условием обеспечения более низкой стоимости выполнения. Аутсорсинг позволяет предприятиям с небольшим числом сотрудников существенно увеличить объемы выполненных работ. Он также может быть рассмотрен с позиции передачи стороннему подрядчику некоторых бизнес-функций или частей бизнес-процесса компании. Так, в настоящее время, ведение бухгалтерского учета и отчетности на многих малых предприятиях осуществляют специализированные организации.

Таким образом, на сегодняшний день для малого и среднего бизнеса существуют различные альтернативные способы финансирования деятельности, помимо традиционных, и их актуальность в условиях сложившейся непростой экономической ситуации, безусловно, возрастает. Международный опыт показывает, что именно с помощью малого бизнеса возможны позитивные изменения в стабилизации и развитии национальной экономики. Именно поэтому необходимо создавать все условия для полноценного внедрения альтернативных форм финансирования в существующую экономическую действительность.

\section{Baikal Research Journal}

электронный научный журнал Байкальского государственного университета 


\section{Список использованной литературы}

1. Кононков Н. П. Малый бизнес как источник экономического роста / Н. П. Кононков, С. В. Ширяева // Проблемы теории и практики управления. — 2014. — № 9. — С. 114-119.

2. Киреенко А. П. Применение программно-целевого метода для государственной поддержки малого и среднего предпринимательства в регионах сибирского округа / А. П. Киреенко, Л. В. Санина // Известия Иркутской государственной экономической академии. 2014. — № 4 (96). - С. 117-132.

3. Санина Л. В. Опыт оказания государственной поддержки субъектам малого и среднего предпринимательства в регионах России [Электронный ресурс] / Л. В. Санина // Известия Иркутской государственной экономической академии (Байкальский государственный университет экономики и права). - 2014. - № 3. - Режим доступа : http://brj-bguep.ru/ reader/article.aspx $? \mathrm{id}=19113$.

4. Ладыгин В. В. Практика бизнес-инкубирования и поддержка малого предпринимательства на муниципальном уровне в России / В. В. Ладыгин. - Саарбрюккен : LAPLAMBERT Academic Publishing, 2013. - 213 c.

5. Чистякова О. В. Инновационные направления развития предпринимательства в Байкальском регионе / О. В. Чистякова. - Иркутск : Изд-во БГУЭП, 2012. - 206 с.

6. Миндич Д. А. Финансы растущего бизнеса / Д. А. Миндич. - М. : Эксперт РА, 2009. - 336 c.

7. Кислицына Л. В. Финансирование предприятий региона в условиях их структурирования : автореф. дис. ... канд. экон. наук : 08.00.10 / Л. В. Кислицына. - Иркутск, 2006. - 20 с.

8. Суходолов А. П. Особенности финансирования субъектов малого бизнеса с применением лизинговой схемы / А. П. Суходолов, И. В. Кульдюкова // Известия Иркутской государственной экономической академии. - 2011. — № 3 (77). - С. 22-25.

9. Полещук О. В. Венчурное финансирование инновационных проектов / О. В. Полещук // Приоритетные направления развития науки и образования : материалы VI Междунар. науч.-практ. конф. - Чебоксары : Центр науч. сотрудничества Интерактив плюс, 2015. Вып. 3 (6). - С. 340-343.

10. Цветкова Е. С. Краудфандинг как инструмент инвестирования / Е. С. Цветкова, В. М. Ганеева // Экономика и управление в XXI веке: тенденции развития. - 2014. № 19-2. - С. 83-88.

11. Киселев Д. А. Краудинвестинг как источник финансирования малого бизнеса в условиях кризиса / Д. А. Киселев, Е. А. Фоканова // Science Time. — 2015. — № 11 (23). C. 246-250.

\section{References}

1. Kononkov N. P., Shiryayeva S. V. Small business as source of economic growth. Problemy teorii i praktiki upravleniya = Problems of Theory and Practice of Management, 2014, no. 9, pp. 114-119. (In Russian).

2. Kireenko A. P., Sanina L. V. Application of program-targeted method for small and medium-sized business state support in the regions of the Siberian Federal District. Izvestiya Irkutskoi gosudarstvennoi ekonomicheskoi akademii = Izvestiya of Irkutsk State Economics Acade$m y, 2014$, no. 4 (96), pp. 117-132. (In Russian).

3. Sanina L. V. Experience of giving state support to small and medium-sized business entities in Russian regions. Izvestiya Irkutskoi gosudarstvennoi ekonomicheskoi akademii (Baykalskii gosudarstvennyi universitet ekonomiki i prava) = Bulletin of Irkutsk State Economics Academy (Baikal State University of Economics and Law), 2014, no. 3. Available at: http://brj-bguep.ru/ reader/article.aspx?id=19113. (In Russian).

4. Ladygin V. V. Praktika biznes-inkubirovaniya i podderzhka malogo predprinimatel'stva na munitsipal'nom urovne $v$ Rossii [Practice of business incubation and support of small businesses at municipal level in Russia]. Saarbryukken, LAPLAMBERT Academic Publishing, 2013. 213 p.

5. Chistyakova O. V. Innovatsionnye napravleniya razvitiya predprinimatel'stva $v$ Baikal'skom regione [Innovative trends of business development in Baikal Region]. Irkutsk, Baikal State University of Economics and Law Publ., 2012. 206 p.

6. Mindich D. A. Finansy rastushchego biznesa [Finance of growing business]. Moscow, Ekspert RA Publ., 2009. 336 p.

\section{Baikal Research Journal}

электронный научный журнал Байкальского государственного университета 
7. Kislitsyna L. V. Finansirovanie predpriyatii regiona $v$ usloviyakh ikh strukturirovaniya. Avtoref. Kand. Diss. [Funding of regional businesses in terms of their structuring. Cand. Diss. Thesis]. Irkutsk, 2006. 20 p.

8. Sukhodolov A. P., Kul'dyukova I. V. Peculiarities of financing small business using leasing scheme. Izvestiya Irkutskoi gosudarstvennoi ekonomicheskoi akademii = Bulletin of Irkutsk State Economics Academy, 2011, no. 3 (77), pp. 22-25. (In Russian).

9. Poleshchuk O. V. Venture financing of innovative projects. Prioritetnye napravleniya razvitiya nauki i obrazovaniya. Materialy VI Mezhdunarodnoi nauchno-prakticheskoi konferentsii [Priority trends of developing science and education. Materials of the 6 th International Scientific Conference]. Cheboksary, Center for Scientific Cooperation Interactive plus Publ., 2015, iss. 3 (6), pp. 340-343. (In Russian).

10. Tsvetkova E. S., Ganeyeva V. M. Crowd funding as instrument of investment. Ekonomi ka i upravlenie $v$ XXI veke: tendentsii razvitiya = Economy and Management in XXI Century: Development Trends, 2014, no. 19-2, pp. 83-88. (In Russian).

11. Kiselev D. A., Fokanova E. A. Crowd-investing as a source of funding small businesses in terms of crisis. Science Time, 2015, No. 11 (23), pp. 246-250. (In Russian).

\section{Информация об авторах}

Кислицына Лариса Викторовна - кандидат экономических наук, доцент, кафедра финансов, Байкальский государственный университет, 664003, г. Иркутск, ул. Ленина, 11, e-mail:visnip@mail.ru.

Суворов Никита Сергеевич - аспирант, кафедра финансов, Байкальский государственный университет, 664003, г. Иркутск, ул. Ленина, 11, e-mail: atikin.2011@mail.ru.

\section{Authors}

Larisa V. Kislitsyna - PhD in Economics, Associate Professor, Chair of Finance, Baikal State University, 11 Lenin St., 664003, Irkutsk, Russian Federation; e-mail: visnip@mail.ru.

Nikita S. Suvorov - PhD Student, Chair of Finance, Baikal State University, 11 Lenin St., 664003, Irkutsk, Russian Federation; e-mail: atikin.2011@mail.ru.

\section{Библиографическое описание статьи}

Кислицына Л. В. Актуальные вопросы организации процесса финансирования предприятий малого бизнеса / Л. В. Кислицына, Н. С. Суворов // Baikal Research Journal. — 2016. T. 7, № 5. - DOI : $\underline{10.17150 / 2411-6262.2016 .7(4) .7 . ~}$

\section{Reference to article}

Kislitsyna L. V., Suvorov N. S. Topical issues of the small business funding organizational process. Baikal Research Journal, 2016, vol. 7, no. 5. DOI : 10.17150/2411-6262.2016.7(4).7. (In Russian).

\section{Baikal Research Journal}

